disinfection of infected linen $\left(65^{\circ} \mathrm{C}\right.$ for 10 minutes). It must be emphasised that our tests assessed the effect of heat in the absence of a cleaning effect, which in practice will very much reduce the load of bacterial contamination. Recent in situ studies failed to demonstrate survival of enterococci in a modern hospital laundry system. ${ }^{9}$ Nevertheless, it may be appropriate to use the higher $\left(71^{\circ} \mathrm{C}\right)$ temperature for the laundry process whenever possible. $E$ faecium isolates were more resistant to heat than the two $E$ faecalis control strains. Overall, we found $E$ faecium isolates to be less heat tolerant than others have suggested. ${ }^{510}$ These differences are almost certainly due to a combination of variations in methodology and interpretation of $\log$ reductions, rather than major strain variations in heat tolerance. These methodologies take no account of the washing effect of medical disinfection processes and we consider that current disinfection guidelines are satisfactory.

Isolates of VRE were provided by Dr B A Oppenheim, Manchester Public Health Laboratory. We thank Dr $\mathrm{H}$ Panigrahi for his support in carrying out this study.
1 Boyce JM, Opal SM, Chow JW, Zervos MJ, Potter-Bynoe G, Sherman CB, et al. Outbreak of multi-resistant Enterococcus faecium with transferable vanB class vancomycin resistance. 7 Clin Microbiol 1994;32:1 148-53.

2 Livornese LL Jr, Dias S, Samel C, Romanowski B, Taylor S, May $\mathrm{P}$, et al. Hospital-aquired infection with vancomycin resistant Enterococcus faecium transmitted by electronic thermometres. Ann Intern Med 1992;117:112-16.

3 Gould FK, Freeman R. Nosocomial infection with microsphere beds. Lancet 1993;342:241-2.

4 Freeman R, Kearns AM, Lightfoot NF. Heat resistance of nosocomial enterococci. Lancet 1994;344:64-5.

5 Kearns AM, Freeman R, Lightfoot NF. Nosocomial enterococci: resistance to heat and sodium hypochlorite. 7 Hosp Infect 1995;30: 193-9.

6 Department of Health and Social Security and the Welsh Office. Hospital Laundry arrangments for used and infected linen. HC(87)30. London: HM Stationery Office 1987. (Renewed until 1993 under letter dated Dec 3, 1992.)

7 Washer disinfectors for medical purposes. BS 2745, part 2 British Standards Institution, 1993.

8 Chadwick PR, Oppenheim BA. Vancomycin-resistant enterococci and bedpan washer machines. Lancet 1994;344:685.

9 Wilcox MH, Jones BL. Enterococci and hospital laundry. Lancet 1995;345:594.

10 Bradley CR, Fraise AP. Abstract P4.2. Second biennial conference of The Federation of Infecton Societies, 1995. $\mathcal{J}$ Infect 1996;32:79.

\title{
The hidden increase in histopathologists' workload
}

\author{
D M Parham
}

\begin{abstract}
The informational content of histopathological reports generated between 1985 and 1995 was assessed. This showed an exponential rise over the past five years. It is postulated that this has arisen from developments in medical science and demands from clinical colleagues. This increase in workload is not addressed by present methods of measurement and has major resource implications.

(F Clin Pathol 1996;49:689-690)
\end{abstract}

Keywords: workload, histopathology.

Histopathologists, like other doctors, are under increasing pressure of work. This includes not only their routine work but also teaching, research, continuing medical education, quality assurance, management, administration, and audit. In histopathology the routine work can be crudely quantified by the number of requests. A more formal unit of measurement is the Welcan system. ${ }^{1}$ This measures the technical requirements in processing the specimen but does not assess a pathologist's input in interpreting or reporting the specimen. This study has examined the increase in the amount of information contained in histopathological reports over the past decade to determine what contribution this has made to the increased workload.

\section{Methods}

In East Dorset there is a combined histopathological department serving Poole and Royal Bournemouth Hospitals. Between 1985 and 1995 histopathological reports for all specimens received at the Royal Bournemouth Hospital during the first two complete weeks (Monday to Friday) in February in selected years were examined. All reports were handwritten by the pathologists prior to typing. The number of items of information recorded were quantified. A point of information included details of the nature of the specimen, measurement, histological description, diagnosis, grade, individual prognostic factors, excision margins, etc. During the weeks of the study in 1985, 1990 and 1992 there were three reporting consultant histopathologists. Two of these subsequently retired and their positions were filled by younger consultants. In 1993 there were four and 1995 five consultant histopathologists.
Accepted for publication 7 May 1996

\section{Department of
Pathology, Royal Hospital, Bournemouth BH7 DW}


Curve fitting and statistical analysis were performed using Microsoft Excell version 5.0 (Microsoft Corporation) on an IBM compatible PC.

\section{Results}

The findings indicate that over the past five years the amount of information per report has increased on average by $7 \%$ (fig 1). In 1985 the amount of information per report ranged from 1 unit (for example, products of conception confirmed) to 25 units (right hemicolectomy containing two different infiltrative carcinomas). By contrast, in 1995 the amount of information per report ranged from 1 unit of information (for example, products of conception confirmed) to 41 units of information (series of colonic biopsy specimens in ulcerative colitis with dysplasia), which included suggestions for further patient management. This increase in information per report, compounded with the increasing number of specimens received by the department, has resulted in an exponential rise in the amount of information generated by pathologists annually (fig 2).

\section{Discussion}

The increasing complexity of pathologists' workload is generally appreciated but little for-

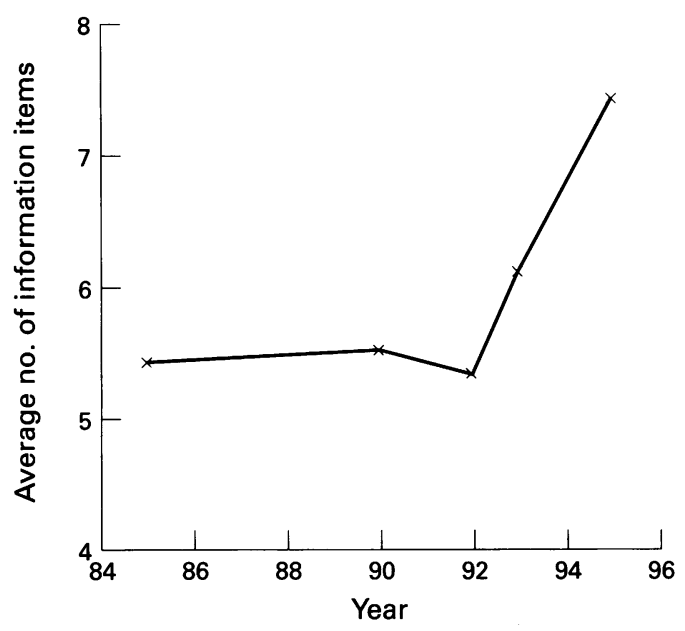

Figure 1 Average number of information items per report.

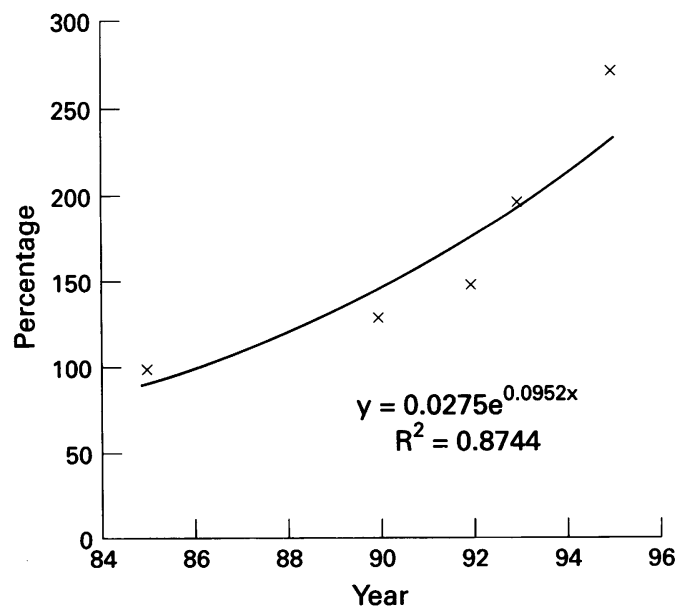

Figure 2 Percentage change in amount of information output (number of requests multiplied by average number of information items) by the department (1985 equal to $100 \%$ ). mal assessment has been performed. Cross and Bull $^{2}$ have shown an almost linear increase in the information content of reports for colectomy and mastectomy specimens in a teaching hospital, amounting to $273 \%$ over a 50 year period. The present study has examined all specimens (of which approximately $15 \%$ are malignancies) reported in a district general hospital and has demonstrated that there has been a significant increase in the information generated by the histopathology department over recent years. This figure will no doubt increase with the drive towards standardised surgical pathology reports, which include checklists of important parameters requiring assessment. $^{3}$

No value judgement was made on the information provided in the reports. Furthermore, the method used may still underestimate the o amount of work involved in reporting the specimen as some particularly complex cases may evoke only a short report. The reasons for 0 the informational increase is speculative. It is $\infty$ reputed that medical knowledge doubles every seven to 10 years. This is reflected in the discovery of new disease entities, the increasing $\vec{\nabla}$ subclassification of diseases and elucidation of new prognostic factors. Increasingly complex $\frac{c}{\omega}$ medical conditions are dealt with in district general hospitals and our consultant colleagues expect pathologists to provide a similar level of expertise, often without the necessary resources. Interestingly, prior to 1992 the average amount of information per report remained relatively constant. Since that date the hospital has appointed a number of young consultant surgeons and pathologists. In recent years the medicolegal requirements to record accurately the nature of the specimen submitted for an opinion, particularly as the gross specimen is discarded after a number of weeks, has also been highlighted.

This increase in information output has significant resource implications, as the cerebral activity of pathologists remains stable (or slows with age!) in contrast to other more technical 을 specialities utilising computer technologies $\frac{D}{0}$ (which double in processing power each year) where it is easier to achieve efficiency savings. N This crude index of a pathologist's activity $N$ highlights the need for a more accurate assess- N్ల ment in this area. The Royal College of 0 Pathologists recognises the increasing complexity of pathologists' workload but the valid- $\frac{\mathrm{D}}{\Phi}$ ity of a recommended upper limit of $4000 \stackrel{?}{?}$ specimens per year per histopathologist (2000 specimens in teaching hospitals) is question-

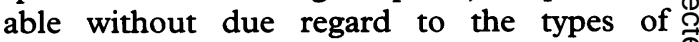
specimens submitted for examination and $\stackrel{\mathbb{Q}}{\varrho}$ clinical demands. ${ }^{4}$

The author thanks Dr M Lesna for her support and comments.

1 DHSS. WELCAN Workload measurement for pathology: manual with schedule of unit values. 1988-89 edn. Cardiff: DHSS, Welsh Office.

2 Cross SS, Bull AD. Is the informational content of histopathological reports increasing? $¥$ Clin Pathol 1992; 45:179-80.

3 Rosai J. Chapter 1. In: Ackerman's Surgical pathology. Vol 1. 8th edn. St Louis, MO: Mosby, 1996:4-5.

4 Royal College of Pathologists. Medical and scientific staffing of National Health Service pathology departments. London: Royal College of Pathologists, April 1992. 